\title{
The proteome of human brain microdialysate
} Martin H Maurer*1, Christian Berger ${ }^{2}$, Margit Wolf ${ }^{2}$, Carsten D Fütterer ${ }^{3}$,
Robert E Feldmann $\mathrm{Jr}^{1}$, Stefan Schwab ${ }^{2}$ and Wolfgang Kuschinsky ${ }^{1}$

Address: ${ }^{1}$ Dept. of Physiology and Pathophysiology, University of Heidelberg, Im Neuenheimer Feld 326, 69120 Heidelberg, Germany, ${ }^{2}$ Dept. of Neurology, University of Heidelberg, Im Neuenheimer Feld 400, 69120 Heidelberg, Germany and ${ }^{3}$ Dept. of Anesthesiology and Critical Care Medicine, University of Heidelberg, Faculty of Clinical Medicine Mannheim, Theodor-Kutzer-Ufer, 68167 Mannheim, Germany

Email: Martin H Maurer* - maurer@uni-hd.de; Christian Berger - christian_berger@med.uni-heidelberg.de; Margit Wolf - margit_wolf@tonline.de; Carsten D Fütterer - c.fuetterer@pio1.uni-heidelberg.de; Robert E Feldmann - robert_feldmann@gmx.li; Stefan Schwab - stefan_schwab@med.uni-heidelberg.de; Wolfgang Kuschinsky - wolfgang.kuschinsky@pio1.uni-heidelberg.de

* Corresponding author

Published: I4 December 2003

Proteome Science 2003, 1:7
Received: 22 September 2003

Accepted: 14 December 2003

This article is available from: http://www.proteomesci.com/content///I/7

(C) 2003 Maurer et al; licensee BioMed Central Ltd. This is an Open Access article: verbatim copying and redistribution of this article are permitted in all media for any purpose, provided this notice is preserved along with the article's original URL.

\begin{abstract}
Background: Cerebral microdialysis has been established as a monitoring tool in neurocritically ill patients suffering from severe stroke. The technique allows to sample small molecules in the brain tissue for subsequent biochemical analysis. In this study, we investigated the proteomic profile of human cerebral microdialysate and if the identified proteins might be useful predictors for disease characteristics in stroke for tissue at risk in the contralateral hemisphere. We analysed cerebral protein expression in microdialysate from three stroke patients sampled from the hemisphere contralateral to the lesion. Using a proteomic approach based on two-dimensional gel electrophoresis and subsequent mass spectrometry, we created a protein map for the global protein expression pattern of human microdialyste.

Results: We found an average of $158 \pm 24(N=18)$ protein spots in the human cerebral microdialysate and could identify 95 spots, representing 27 individual proteins. Most of these have been detected in human cerebrospinal fluid before, but 10 additional proteins mainly of cerebral intracellular origin were identified exclusively in the microdialysate.

Conclusions: The 10 proteins found exclusively in human cerebral microdialysate, but not in cerebrospinal fluid, indicate the possibility to monitor the progression of the disease towards deterioration. The correlation of protein composition in the human cerebral microdialysate with the patients' clinical condition and results of cerebral imaging may be a useful approach to future applications for neurological stroke diagnosis, prognosis, and treatment.
\end{abstract}

\section{Background}

Microdialysis is used to monitor changes in the composition of the extracellular fluid in living tissue, measuring the concentrations of small molecules such as neurotransmitters, hormones, ions, or peptides [1-3]. In principle, molecules up to a certain molecular weight cross the semipermeable probe membrane and are collected in the efflu- ent microdialysate, depending on the concentration gradient, the flow velocity of the perfusate, the diffusion coefficients of the molecules, and the permeability of the membrane [1-3]. In the brain, the perfusion fluid is composed of "artificial" CSF, containing ions in the same concentration as in CSF in vivo [1], thus the concentrations of 
molecules found in the microdialysate represent their concentration in the brain tissue.

We have established microdialysis as a monitoring tool for neurotransmitter release and metabolic products in critically ill stroke patients during their intensive care management $[4,5]$. In these studies, the tissue at risk can be monitored with regard to its metabolic status, or cellular damage of the brain by microdialysis and intracranial temperature and pressure measurement in co-interpretation with neuroradiological imaging. The main factor of high diagnostic and prognostic value will need to predict a possibility to rescue the function of the remaining, nondiseased brain tissue, even more importantly, if the infarct core might still be growing towards the penumbral tissue. Therefore, we were interested in the present study in the protein expression profile of human brain microdialysate, as the proteins found in the microdialysate might be related to metabolic status and cellular damage as indicator for the tissue at risk.

Although microdialysis is an important method in monitoring neurological disease, studies investigating protein expression patterns of microdialysate have not been performed yet, but cerebrospinal fluid has been extensively analysed by two-dimensional gel electrophoresis (review in [6]), and about 30-35 different proteins have been identified so far. Two-dimensional gel electrophoresis is a useful instrument to search for changes in the cerebrospinal fluid protein expression pattern in neurological and psychiatric diseases, but it cannot follow the time-course of the disease, as it represents a static measurement at a single given time-point. Moreover, the composition of normal cerebrospinal fluid differs markedly from the composition of extracellular fluids in the brain, including microdialysate [7]. Here, we present for the first time a protein map that is derived from microdialysate of noninfarcted brain tissue of three stroke patients.

\section{Results}

We analysed human brain microdialysate obtained from the contralateral, non-infarcted hemisphere of three stroke patients to create a two-dimensional protein map of microdialysate (Fig. 1). The average protein content in the microdialysis samples of the three patients was $0.21 \pm$ $0.11 \mathrm{~g} / \mathrm{L}$, ranging from 0.083 to $0.395 \mathrm{~g} / \mathrm{L}(N=18$, six samples for each patient) which is comparable to CSF $(0.2$ $\mathrm{g} / \mathrm{L}$ ) [8]. This protein concentration allowed us to use the microdialysate in the two-dimensional gel electrophoresis experiments without further processing or concentration steps.

We separated individual proteins within the cerebral microdialysate by two-dimensional gel electrophoresis according to their isoelectric point and their molecular weight, subsequently followed by mass spectrometry, gel matching and database search to identify the proteins. We found an average of $158 \pm 24(N=18$, six samples for each patient) protein spots in the two-dimensional electrophoresis gels. Of the mapped protein spots, we could identify 95 spots by mass spectrometry and database search, representing 27 individual proteins or protein groups (Table 1). Of these, we have found 10 proteins exclusively in the microdialysate, whereas 17 proteins have been described earlier for cerebrospinal fluid [9]. The 95 protein spots included different isoforms and posttranslational modifications of the proteins, e. g. glycosylation, to alter molecular weight and/or isoelectric point. Unfortunately, it was not possible to obtain mass spectrometry sequence data to reliably identify the missing protein spots.

\section{Discussion}

\section{Human brain microdialysis}

This is the first report on cerebral microdialysis in the human brain analysed by a proteomic approach based on two-dimensional gel electrophoresis and mass spectrometry that describes the molecular pattern of protein expression in the brain microdialysate of three stroke patients. We hope to provide a proteome map for human brain microdialysate which allows both future comparisons between microdialysate samples from different stages of the disease, and between microdialysate and CSF.

In clinical practice, microdialysis has become a useful monitoring technique to detect the development of secondary neuronal ischemia and to assess the potential reversibility of ischemic brain damage [10]. It may be more sensitive than other diagnostic instruments as EEG and somatosensory evoked potentials, however, the method is invasive, and positioning the probes into penumbral tissue, or into the infarct core, may be difficult even with advanced neuroradiological methods, as the microdialysis probes are not radiopaque and the target volume is very small. Thus a direct measurement in the infarct core, or penumbral tissue, is technically difficult and limited in its diagnostic and prognostic value. On the other hand, it may be even more interesting to determine the metabolic status of not yet infarcted tissue at risk of ischemia. Therefore the implantation of a microdialysis probe in the non-infarcted hemisphere may contribute to the prognostic monitoring of the non-diseased hemisphere to indicate possible necessary therapeutical intervention, like craniotomy, hypothermia etc. We have already established this monitoring for small molecules like neurotransmitters and metabolites $[4,5,11]$ during hypothermic treatment, where microdialysis allowed to assess the patient's current status and to predict further deterioration which is subsumed as "malignant" cerebral infarction. Therefore, we were interested in the present 


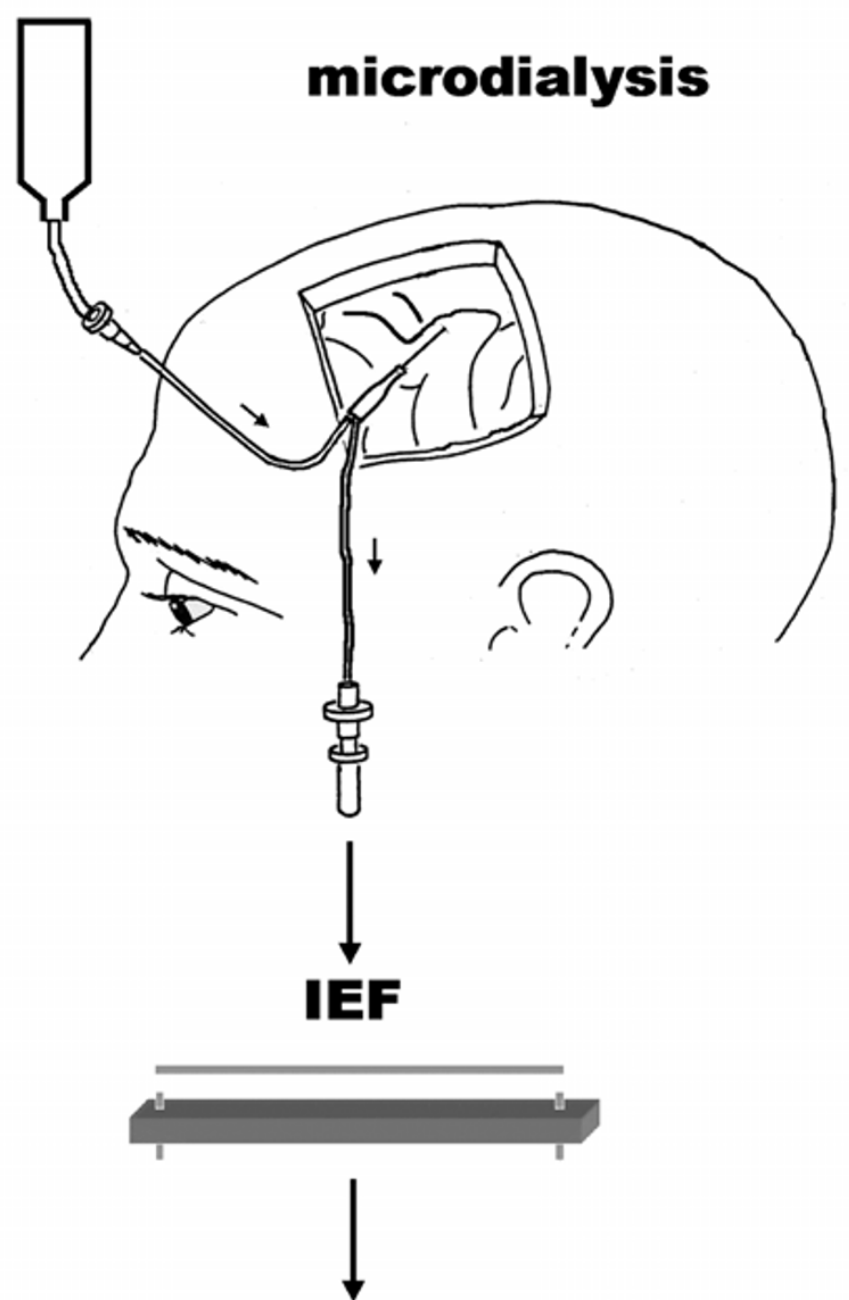

\section{SDS-PAGE}

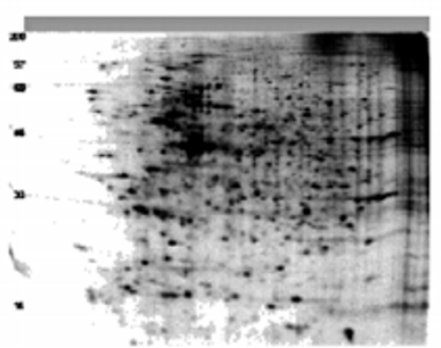

Figure I

Schematic principle of microdialysate sampling and two dimensional electrophoresis. Following the parietal implantation of the microdialysis catheter, a small volume of microdialysate is collected. The microdialysate sample is subjected two-dimensional gel electrophoresis with first dimension IEF and second dimension SDS-PAGE. Gels were stained and individual protein spots were analysed by mass spectrometry. 
Table I: Proteins identified in the human cerebral microdialysate. The upper part contains proteins also found in CSF, the lower part lists additional proteins found in the microdialysate which have not been described in CNS. The first column gives the consecutive number of the identified protein, the second column the number of spots in the two-dimensional gels belonging to the individual proteins. The third and fourth column displays the protein annotation as in the SwissProt database at http://www.expasy.ch. The amino acid composition or structural information about the proteins can be retrieved via the accession number in the fifth column. This database also contains the CSF protein map. The sixth and seventh column shows pl and molecular weight. Strictly speaking, the immunoglobulin fractions do not represent a single protein, but a protein family, therefore $\mathrm{pl}$ and molecular weight cannot be given.

\begin{tabular}{|c|c|c|c|c|c|c|}
\hline Spot number & $\begin{array}{l}\text { Number of spots } \\
\text { identified }\end{array}$ & Gene name & Protein description & $\begin{array}{l}\text { SwissProt accession } \\
\text { number }\end{array}$ & Theoretical pl & $\begin{array}{l}\text { Theoretical molecular } \\
\text { weight }(\mathrm{Da})\end{array}$ \\
\hline \multicolumn{7}{|c|}{ proteins identified in cerebral microdialysate and cerebrospinal fluid } \\
\hline 1 & 8 & SERPINA3 & Alpha-I-antichymotrypsin & POIOII & 5.33 & 47651 \\
\hline 2 & 8 & SERPINAI & Alpha-I-antitrypsin & P01009 & 5.37 & 46737 \\
\hline 3 & 5 & AIBG & Alpha-IB-glycoprotein & P042I7 & 5.65 & 51941 \\
\hline 4 & 3 & APOAI & Apolipoprotein A-I & P02647 & 5.56 & 30778 \\
\hline 5 & 1 & AMBP & AMBP protein & $\mathrm{P} 02760$ & 5.95 & 38999 \\
\hline 6 & 2 & APOE & Apolipoprotein E & P02649 & 5.65 & 36154 \\
\hline 7 & 2 & $\mathrm{C} 3$ & Complement $\mathrm{C} 3$ & POI024 & 6.02 & 187164 \\
\hline 8 & 1 & FGG & Fibrinogen gamma chain & P02679 & 5.37 & 51512 \\
\hline $9 a$ & 6 & HP & Haptoglobin-2 & P00738 & 6.13 & 45205 \\
\hline $9 b$ & 2 & $\mathrm{HP}$ & Haptoglobin alpha-2 chain & P00738 & 5.57 & 15946 \\
\hline $9 c$ & 2 & $\mathrm{HP}$ & Haptoglobin beta chain & P00738 & 6.32 & 27265 \\
\hline 10 & 7 & -- & Immunoglobulin heavy chain & P99006 & -- & -- \\
\hline II & 13 & -- & Immunoglobulin light chain & P99007 & -- & -- \\
\hline 12 & 1 & RBP4 & Plasma retinol-binding protein & $\mathrm{P} 02753$ & 5.76 & 23044 \\
\hline 13 & 4 & PLG & Plasminogen (EC 3.4.21.7) & P00747 & 7.04 & 90569 \\
\hline 14 & 5 & ALB & Albumin & P02768 & 5.92 & 69367 \\
\hline 15 & 5 & $\mathrm{TF}$ & Transferrin & $\mathrm{P} 02787$ & 6.81 & 77050 \\
\hline 16 & 2 & TTR & Transthyretin & P02766 & 5.52 & 15887 \\
\hline 17 & 2 & GC & Vitamin D-binding protein & P02774 & 5.24 & 56761 \\
\hline \multicolumn{7}{|c|}{ proteins identified solely in cerebral microdialysate } \\
\hline 18 & 1 & $\mathrm{~B} 2 \mathrm{M}$ & Beta-2 microglobulin & P0I887 & 7.80 & 13823 \\
\hline 19 & 1 & CKB & Creatine kinase, $B$ chain & PI 2277 & 5.34 & 43644 \\
\hline 20 & 1 & DRP2 & Dihydropyrimidinase related protein-2 & Q16555 & 5.95 & 62294 \\
\hline 21 & 4 & GAPD & Glyceraldehyde 3-phosphate dehydrogenase & PI6858 & 8.45 & 35679 \\
\hline 22 & 1 & HSP73 & Heat shock protein 70 kD HSP73 & $\mathrm{PIII42}$ & 5.37 & 70898 \\
\hline 23 & 1 & $\mathrm{HBB}$ & Hemoglobin beta chain & P02023 & 6.81 & 15867 \\
\hline 24 & 1 & MDHA & Malate dehydrogenase & P40925 & 6.89 & 36295 \\
\hline 25 & 4 & TUBAI & Tubulin alpha-I & P04687 & 4.94 & 50152 \\
\hline 26 & 3 & -- & Tubulin beta & Q13885 & 4.78 & 49907 \\
\hline 27 & 1 & TUBB5 & Tubulin beta 5 & Q8WUCI & 4.78 & 49671 \\
\hline
\end{tabular}

study in the protein expression pattern of human brain microdialysate, as the proteins found in the microdialysate might give insight into the metabolic status and cellular damage of the brain.

With regard to protein recovery, we found that the predicted cut-off value of the dialysis membrane of $20 \mathrm{kDa}$ could not prevent even high-molecular weight proteins (up to $180 \mathrm{kDa}$ ) from passing through the membrane. The cut-off is defined as the molecular weight at which $80 \%$ of the molecules are prevented from passing through the dialysis membrane [12]. This means that molecules larger than $20 \mathrm{kDa}$ are not excluded from the microdialysate, but their presence is more unlikely, or their concentration in the sample is smaller than in the extracellular fluid. The term protein recovery describes the protein concentration found in the microdialysate compared to the brain extracellular fluid. Protein recovery depends on the length and diameter of the membrane, the flow rate of the perfusion fluid, temperature and $\mathrm{pH}$, molecular weight, shape, and charge of the molecules influencing the diffusion coefficient, and the binding of the proteins to the membrane and the tubing, and possible degradation of the proteins [13-15]. In our interpretation, the specific geometry of the custom-made microdialysis membrane (diameter $0.65 \mathrm{~mm}$, length $10 \mathrm{~mm}$ ) could contribute to the finding of proteins larger than the formal cut-off of 20 $\mathrm{kDa}$.

\section{Microdialysis in stroke patients}

Extensive brain infarction and subsequent brain edema formation are neurological disorders requiring intensive care treatment but still present a mortality of up to $80 \%$ [16]. Various treatment measures, such as osmotic agents, craniotomy, and hypothermia, have been investigated to minimize brain edema, reduce mortality, and improve outcome. However, monitoring the efficacy of these measures is often difficult, especially with regard to early prog- 
nostic detection of severe neuronal damage. Microdialysis was developed for neurochemical monitoring and allows measurement of the extracellular concentrations of various endogenous substances, such as excitotoxic amino acids or metabolic end products in short sampling periods of time $[2,17,18]$.

We are aware that there is no "physiological" microdialysate, because obtaining microdialysate from non-diseased volunteers is ethically not practicable and rises major concerns. With regard to the literature, we want to point out that all published microdialysate studies for human brain tissue were performed in patients, not volunteers, where these subjects suffered from severe neurological deficits, and received a number of treatments, including craniotomy, or hypothermia. Thus we must emphasize that the proteome map of human brain microdialysate as presented here, is collected from non-diseased brain tissue in stroke patients under intensive care conditions and hypothermia. Whether these conditions influence the proteome profile, is unknown.

The patients described in this study showed the clinical and neuroradiological features of a space-occupying hemispheric stroke. CT scan demonstrated extensive brain infarction with severe initial mass effects. Brain edema was treated with hypothermia and osmotic agents, which decreased the edema volume. Hypothermia was considered an experimental rescue therapy, although evidence is increasing that moderate hypothermia is a potent measure to treat brain edema [4]. Neurochemical analysis of small molecules and metabolites sampled from the noninfarcted hemisphere and processed using a HPLC system showed normal values for glutamate $(3.9 \pm 0.3 \mu \mathrm{mol} / \mathrm{L})$, glycerol $(38.9 \pm 1.9 \mu \mathrm{mol} / \mathrm{L})$, lactate $(2.0 \pm 0.1 \mathrm{mmol} / \mathrm{L})$, and pyruvate concentrations $(58.4 \pm 3.3 \mu \mathrm{mol} / \mathrm{L})$ over the sampling period of 18-72 hours [19]. These results indicate that there is no increased cell death and glutamate release in the non-infarcted hemisphere, and that the noninfarcted hemisphere is still not affected by ischemia.

\section{Proteomic approach and comparison to CSF}

In recent years, proteomic approaches have been developed as mass screening tools to evaluate protein expression patterns in various tissues and body fluids $[9,20]$. Cerebrospinal fluid (CSF) has been extensively analysed by two-dimensional gel electrophoresis (2-DE) [21-23], and about 30-35 different proteins have been identified so far. 2-DE proofed to be a useful tool to search for changes in the CSF protein expression pattern in neurological and psychiatric diseases [24], but CSF analysis cannot follow the time-course of the disease, as it represents a static measurement at a single given time-point. The knowledge of the time-course and appearance or disappearance of certain proteins might be useful for prediction of the progression of the disease. Therefore, the combination of microdialysis and proteomics may be a useful instrument.

In the proteomic approach applied in this study, we found an expression pattern of the microdialysate proteins which differed markedly from human cerebrospinal fluid, but most of the proteins identified in the microdialysate have also been detected in cerebrospinal fluid $[9,25]$. We could identify 95 spots out of an average of 158 (60\%) in the two-dimensional gels, representing 27 individual proteins. Due to isoforms and protein modifications such as glycosylation, phosphorylation, etc. the number of proteins actually found is lower than the number of protein spots. Mass spectra producing ambiguous results indicating that there might be 2 or more proteins present in a single spot, did not allow to identify the protein spot precisely, therefore it was classfied as "unindentified" in this study.

\section{Functional role of the identified proteins}

Most of the identified proteins have also been detected in human CSF, as the perfusion solution and therefore the brain microdialysate is composed mostly of CSF, or "artifical" CSF $[7,9,25]$. We found 10 additional proteins, which were mainly of intracellular origin (Table 1, lower part). Of these, creatine kinase $B$ subunit and tubulin alpha- 1 were brain-specific proteins, indicating that these proteins are not of intravascular, circulatory, or CSF origin. When comparing the human CSF map to the human microdialysate map, the differences found could be attributed to the composition of microdialysate as an filtrate of CSF, but the additional proteins (Table 1, lower part) may enable the monitoring of brain function and brain cell status in vivo in a future application. It would be a desirable aim to have a diagnostic or prognostic tool for early detection of "malignant" cerebral infarction, which, as opposed to non-malignant cerebral infarction, needs a different type and intense of treatment.

The 10 proteins found exlusively in microdialysate, not in CSF, are unlikely to be the result of tissue injury due to the microdialysis probe as microdialysate sampling did not begin until 18 hours after probe insertion. Furthermore, since the stroke patients show imaging evidence of edema formation that may be compromising perfusion in the contralateral hemisphere and inducing tissue injury, these proteins may indeed be coming from the ipsilateral hemisphere that is undergoing injury. Their appearance could also be the result of tissue compression and developing injury in the contralateral hemisphere due to the expanding edema formation.

We found proteins in the microdialysate which are located intracellularly under physiological conditions. 
There might be several explanations for their appearance in the microdialysate: (1) A large number of cells might be compromised in the non-stroke lesioned hemisphere, indicating that the tissue in the hemisphere contralateral to the stroke is already at risk of becoming lesioned. (2) The proteins originate from the lesioned hemisphere, but the ways of transport remain unknown. The appearance of many CSF proteins may also indicate a lesion of the blood-brain barrier, but the similarity of microdialysate and CSF is more likely explained by the contribution of CSF as major component of the extracellular fluid to the sampling process of microdialysis. (3) The implantation of the microdialysis probe contributes to this finding by lesioning tissue in the contralateral hemisphere.

The functional role of the 10 proteins identified exclusively in the microdialysate (Table 1 , lower part) is known from the biochemical pathways they are integrated in. However, as we learn more about function and location of proteins, there is a reappraisal in some functional aspects of proteins: A protein does not only have a single function, indeed most proteins seem to have several functions, e. g. in transport, regulation of enzyme activity, or activation of biological systems, depending on the protein's location and the microenvironmental conditions. For example, hemoglobin which we have found in the microdialysate, does not only transport oxygen and carbon dioxide but also plays a role as a potent NO detoxifier and oxygen scavenger, in addition to the regulation of blood $\mathrm{pH}$ and of regional blood flow $[26,27]$.

\section{Conclusions}

The first step in this research program was to provide a proteome map in human cerebral microdialysate. Based on these mapping data, future investigations will focus on the biological meaning of the identified proteins as valuable markers for diagnosis and prognosis, or even therapeutical approach. The combination of microdialysis, two-dimensional gel electrophoresis, and mass spectrometry revealed a characteristic spot pattern for human cerebral microdialysate and is an applicable method to analyse this body fluid. Ten proteins have been found in the microdialysate which have not been observed in CSF. Most of the proteins found exclusively in the microdialysate are of intracellular origin, indicating a relationship between protein concentration in the microdialysate and tissue damage. The different samples ( 6 each in 3 patients) showed a high reprocibility. Unfortunately, the limited number of samples did not allow to conduct timecourse analysis due to statistical reasons. To draw conclusions with regard to differential analysis of protein concentrations, a larger number of patients has to be analysed. In principle, it would also be of interest to monitor the time-course of protein spot patterns in neurological diseases, such as stroke. The possible correlation of concentrations of certain proteins in the human cerebral microdialysate with the patients' clinical condition and with the results of the cerebral imaging (CCT, MRI) may be a useful approach to future applications for neurological stroke diagnosis and treatment.

\section{Patients and methods}

Flexible microdialysis probes with a formal cut-off level of $20 \mathrm{kDa}$ (membrane diameter $0.65 \mathrm{~mm}$, membrane length $10 \mathrm{~mm}$ ) (CMA/70 custom probes, CMA Microdialysis, Solna, Sweden) and an intracranial pressure measuring device (Spiegelberg, Hamburg, Germany) were inserted into the fronto-parietal parenchyma of three patients with severe hemispheric stroke. Microdialysate in the present study was collected from the non-diseased, contralateral hemisphere. All patients were part of an open, prospective observational study [4] on neurochemical monitoring of brain tissue that was approved by the local Ethics Committee (approval number 34/97) and required written consent by the patient's next of kin according to the Declaration of Helsinki. Patients were male and aged 32, 42, and 63. Initial CCT and MRI scan demonstrated complete infarction of the left middle cerebral artery territory with attenuated hemispheric perfusion and impending mass effect due to edema formation. We included patients with a hypodensity in the initial CT scan exeeding two thirds of the MCA territory. Developing brain edema on CT was diagnosed by hypodensity and midline shift. Midline shift was considered significant when reaching more than 1 $\mathrm{cm}$. MRI showed hypointense signals in the MCA territory and a matching deficit in the diffusion- and perfusionweighted images. The penumbral zone was defined by the area of a perfusion-diffusion mismatch. The patients were analgosedated, mechanically ventilated and were treated initially with mild hypothermia $\left(33^{\circ} \mathrm{C}\right)$ as rescue therapy. All three patients passed away after several days of intensive care treatment due to their severe brain damage.

Microdialysis was performed as described $[4,5,11]$. Briefly, the microdialysis probes were perfused at $0.3 \mu \mathrm{L} /$ min with a sterile CSF equivalent solution consisting of $147 \mathrm{mmol} / \mathrm{L} \mathrm{NaCl}, 2.7 \mathrm{mmol} / \mathrm{L} \mathrm{KCl}, 1.2 \mathrm{mmol} / \mathrm{L} \mathrm{CaCl}_{2}$, and $0.85 \mathrm{mmol} / \mathrm{L} \mathrm{MgCl}_{2}$ (CNS perfusion fluid, CMA Microdialysis, Solna, Sweden).

Microdialysis fluid was sampled in vials replaced every 60 to $120 \mathrm{~min}$. The samples used in this study were obtained in a timecourse of $18-72 \mathrm{~h}$ after implantation of the microdialysis probes. After immediate neurochemical analysis, vials were stored at $-20^{\circ} \mathrm{C}$ for post hoc proteome analysis. Total protein content in the undiluted microdialysis samples was measured by the MicroBCA assay (Pierce, Rockford, Illinois, U.S.A.). 


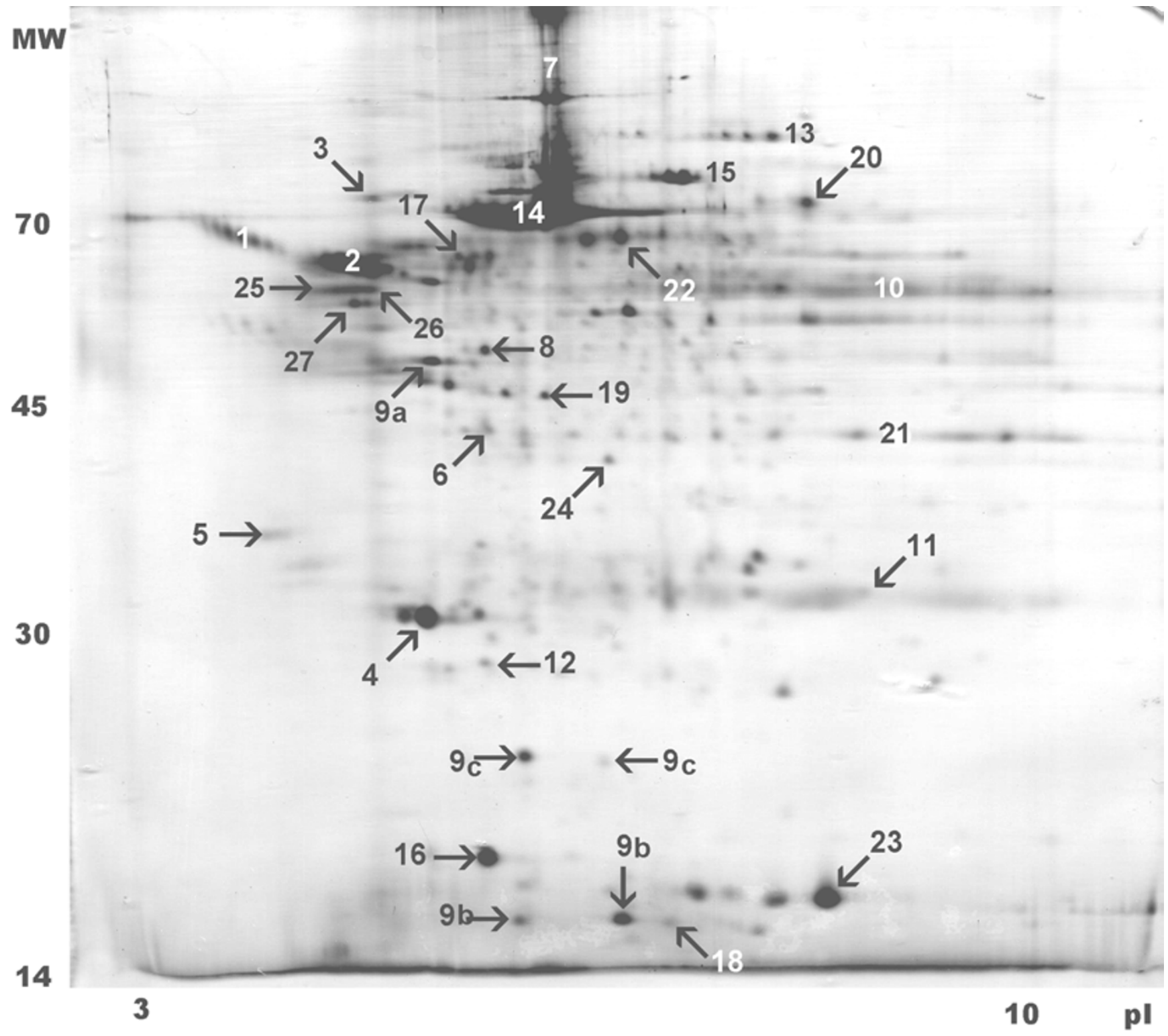

\section{Figure 2}

Two-dimensional electropherogram of human microdialysate. This figure shows a real image sample of a cerebral microdialysate electrophoresis gel with annotated gel spots. We found an average of I58 \pm 24 protein spots in the gels $(N=$ I8), of which 95 could be identified by subsequent mass spectrometry and database search, representing 27 different proteins.

Two-dimensional gel electrophoresis was performed essentially in accordance with standard protocols $[28,29]$ and as described previously in detail [30]. Briefly, microdialysate samples were centrifugated for $5 \mathrm{~min}$ at maximum speed on a table centrifuge to remove disturbing substances such as cell debris. 5-10 $\mu \mathrm{L}$ (corresponding to $1-2 \mu \mathrm{g}$ ) of the microdialysate were suspended in $6 \mathrm{M}$ urea, $2 \mathrm{M}$ thiourea, 2\% CHAPS, $0.5 \%$ IPG buffer $\mathrm{pH}$ 3-10
(Amersham Biosciences, Uppsala, Sweden), and a trace of bromophenol blue, resulting in a final volume of $350 \mu \mathrm{L}$. Samples were applied to $\mathrm{pH}$ 3-10 non-linear gradient isoelectric focussing gel strips (Immobiline DryStrip pH 3$10 \mathrm{NL}, 18 \mathrm{~cm}$ ) in the IPGphor apparatus (both Amersham Biosciences, Uppsala, Sweden) with 12 hours of reswelling at $30 \mathrm{~V}$, then $200 \mathrm{~V}, 500 \mathrm{~V}$, and $1,000 \mathrm{~V}$ for 1 hour each. Voltage was increased to $8,000 \mathrm{~V}$ in $30 \mathrm{~min}$ and kept 
constant at $8,000 \mathrm{~V}$ for 12 hours, resulting in a total of $100,300 \mathrm{Vh}$. The gel strips were equilibrated for $20 \mathrm{~min}$ each in $1 \%$ dithiothreitol or $2.5 \%$ iodoacetamide, respectively, followed by a non-gradient, $12.5 \%$ polyacrylamide gel electrophoresis in the presence of $0.1 \%$ sodium dodecyl sulfate. Gels were run at $30 \mathrm{~mA}$ for $30 \mathrm{~min}$ and $100 \mathrm{~mA}$ for about $4 \mathrm{~h}$ in a $20 \mathrm{~cm} \times 20 \mathrm{~cm}$ water-cooled vertical electrophoresis apparatus. Six gel electrophoresis replicates were run for each patient.

For image analysis, gels were silver stained [31] and digitized in a desktop scanner. Images were analysed densitometrically by the Phoretix 2D Elite software (Nonlinear Dynamics, Newcastle-upon-Tyne, UK), and gel matching was performed as described [30].

For mass spectrometry, gels were stained using colloidal Coomassie Brilliant Blue [32]. Spots of interest were excised, and mass spectrometry and data acquisition were performed by the mass spectrometry group of the University of Heidelberg's Center for Molecular Biology (ZMBH) using MALDI-TOF mass spectrometry (Reflex III, Bruker Daltonics, Bremen, Germany) instrumentation. Mass spectra were compared to the Mascot database http:// www.matrixscience.com[33] to identify peptide sequences.

\section{List of abbreviations}

2-D, two-dimensional;

2-DE, two-dimensional electrophoresis;

CHAPS, 3-[(3-cholamidoproplyl)dimethylammonio]-1propanesulfonate;

CSF, cerebrospinal fluid;

CT, computer tomography;

CCT, cranial computer tomography;

IEF, isoelectric focussing;

MALDI-TOF, matrix-assisted laster desorption/ionizationtime of flight mass spectrometry;

MRI, magnetic resonance imaging;

MS, mass spectrometry;

SDS-PAGE, sodium dodecylsulfate polyacrylamide gel electrophoresis;

\section{Competing interests}

The authors declare no competing financial interests in this study.

\section{Author's contributions}

MHM established 2-DE techniques and MHM, REF, and CDF performed the 2-DE experiments and improved and performed image analysis and created the database. REF supervised mass spectrometry. CB, MW and SS collected the samples. WK and SS conceived the study and participated in the design and coordination of the experiments. All authors have read and approved the final manuscript.

\section{Acknowledgements}

The authors thank Mrs. Inge Keller for technical assistance. This study was supported by the German Ministry of Education and Research (BMBF, Kompetenznetz Schlaganfall, B2 (to WK) and B7 (to SS)).

\section{References}

I. Ungerstedt U: Measurement of neurotransmitter release by intracranial dialysis. In: Measurement of Neurotransmitter Release in Vivo 6 Volume 6. Edited by: Marsden CA. Chichester: Wiley; 1984:8I-105.

2. Ungerstedt U: Microdialysis - principles and applications for studies in animals and man. J Int Med I99I, 230:365-373.

3. Benveniste H: Brain microdialysis. J Neurochem 1989, 52:1667-1679.

4. Berger C, Schäbitz W-R, Georgiadis D, Steiner T, Aschoff A, Schwab $S$ : Effects of hypothermia on excitatory amino acids and metabolism in stroke patients - a microdialysis study. Stroke 2002, 33:5I 9-524.

5. Berger C, Annecke A, Aschoff A, Spranger M, Schwab S: Neurochemical monitoring of fatal middle cerebral artery infarction. Stroke 1999, 30:460-463.

6. Rohlff C: Proteomics in molecular medicine: applications in central nervous systems disorders. Electrophoresis 2000, 21:1227-1234.

7. Hamberger A, Nystrom B, Silvenius H, Wikkelso C: The contribution from the choroid plexus and the periventricular CNS to amino acids and proteins in the human CSF. Neurochem Res 1990, 15:307-312.

8. Lentner C: Liquor cerebrospinalis. In: Wissenschaftliche Tabellen Geigy Edited by: Lentner C. Basel: Ciba-Geigy; 1977:161-173.

9. Sanchez J-C, Appel RD, Golaz OG, Pasquali C, Ravier F, Bairoch A, Hochstrasser DF: Inside SWISS-2DPAGE database. Electrophoresis 1995, 16:||3|-||15|.

10. Hillered L, Persson L: Theory and practice of microdialysis prospect for future clinical use. Acta Neurochir Suppl (Wien) 1999, 75:3-6.

II. Schäbitz WR, Berger C, Schellinger PD, Aschoff A, Steiner T, Schwab $S$ : Neurometabolic changes during treatment with moderate hypothermia in a patient suffering from severe middle cerebral artery infarction. Cerebrovasc Dis 200 I, I 2:298-302.

12. CMA Microdialysis AB: The microdialysis technique. 2003 [http:/ /www.microdialysis.se/technique.htm].

13. Eliasson A: Microdialysis - principles of recovery. CMA Application Note I. 1991 [http://www.microdialysis.se/pdffiler/applica tion\%20notes/appnot/www.pdf].

14. Kehr J: In vitro recovery measures of peptides. CMA Application Note 9. 199/ [http://www.microdialysis.se/pdffiler/applica tion\%20notes/appnot9www.pdf].

15. Kehr J: In vivo microdialysis of peptides vasopressin and oxytocin. CMA Application Note 10. 1991 [http://www.microdialy sis.se/pdffiler/application\%20notes/appnot I Owww.pdf].

16. Hacke W, Schwab S, Horn M, Spranger M, De Georgia M, von Kummer R: 'Malignant' middle cerebral artery territory infarction: clinical course and prognostic signs. Arch Neurol 1996, 53:309-315.

17. Hutchinson PJ, O'Connell MT, Kirkpatrick PJ, Pickard JD: How can we measure substrate, metabolite and neurotransmitter 
concentrations in the human brain? Physiol Meas 2002, 23:R75-109.

18. Berger C, Schwab S: "Malignant" or Not: Is There a Role for In Vivo Neurochemistry? Stroke 2003, 34:29|4-29I5.

19. Berger C, Dohmen C, Maurer M, Graf R, Schwab S: Cerebral microdialysis in stroke. Nervenarzt 2003. Epub ahead of print:DOI: I0.1007/s00 I I5-00003-0I627-x

20. Morrison RS, Kinoshita Y, Johnson MD, Uo T, Ho JT, McBee JK, Conrads TP, Veenstra TD: Proteomic analysis in the neurosciences. Mol Cell Proteomics 2002, I:553-560.

21. Marshall T, Williams KM: The simplified technique of high resolution two-dimensional polyacrylamide gel electrophoresis: biomedical applications in health and disease. Electrophoresis | 991, | 2:46|-47|.

22. Davidson P, Paulson L, Hesse C, Blennow K, Nilsson CL: Proteome studies of human cerebrospinal fluid and braintissue using a preparative two-dimensional electrophoresis approach prior to mass spectrometry. Proteomics 200I, I:444-452.

23. Yuan X, Russell T, Wood G, Desiderio DM: Analysis of the human lumbar cerebrospinal fluid proteome. Electrophoresis 2002, 23: II85-1196.

24. Wildenauer DB, Korschenhausen D, Hoechtlen W, Ackenheil M, Kehl M, Lottspeich F: Analysis of cerebrospinal fluid from patients with psychiatric and neurological disorders by twodimensional electrophoresis: identification of disease-associated polypeptides as fibrin fragments. Electrophoresis |99|, 1 2:487-492.

25. Sickmann A, Dormeyer W, Wortelkamp S, Woitalla D, Kuhn W, Meyer HE: Identification of proteins from human cerebrospinal fluid, separated by two-dimensional polyacrylamide gel electrophoresis. Electrophoresis 2000, 21:2721-2728.

26. Imai K: The haemoglobin enzyme. Nature 1999, 40 I:437-439.

27. Stamler JS, Jia L, Eu JP, McMahon TJ, Demchenko IT, Bonaventura J, Gernert K, Piantadosi CA: Blood flow regulation by S-nitrosohemoglobin in the physiological oxygen gradient. Science 1997, 276:2034-2037.

28. Link AJ, ed: 2-D proteome analysis protocols. Totowa, N.J Humana Press 1999.

29. Görg A, Obermaier C, Boguth G, Harder A, Scheibe B, Wildgruber $R$, Weiss $W$ : The current state of two-dimensional electrophoresis with immobilized pH gradients. Electrophoresis 2000 , 21:1037-1053.

30. Maurer MH, Feldmann RE Jr, Fütterer CD, Kuschinsky W: The proteome of neural stem cells from adult rat hippocampus. Proteome Sci 2003, I:4.

3I. Blum H, Beier H, Gross HJ: Improved silver staining of plant proteins, RNA and DNA in polyacrylamide gels. Electrophoresis 1987, 8:93-99.

32. Neuhoff $\mathrm{V}$, Stamm R, Eibl $\mathrm{H}$ : Clear background and highly sensitive protein staining with Coomassie Blue dyes in polyacrylamide gels: A systematic analysis. Electrophoresis 1985, 6:427-448.

33. Perkins DN, Pappin DJ, Creasy DM, Cottrell JS: Probability-based protein identification by searching sequence databases using mass spectrometry data. Electrophoresis 1999, 20:355 I-3567.
Publish with Bio Med Central and every scientist can read your work free of charge

"BioMed Central will be the most significant development for disseminating the results of biomedical research in our lifetime. "

Sir Paul Nurse, Cancer Research UK

Your research papers will be:

- available free of charge to the entire biomedical community

- peer reviewed and published immediately upon acceptance

- cited in PubMed and archived on PubMed Central

- yours - you keep the copyright
BioMedcentral 